\title{
Utilisation of Green Synthesised Silver Nanoparticles for Water Quality Management
}

\author{
P. Dhasarathan ${ }^{1}$, N. Reeshma Devi', P. Sangeetha', Suman Madhu G. Navaraj', \\ A. J. A. Ranjitsingh ${ }^{*}$, C. Padmalatha ${ }^{2}$ \\ ${ }^{1}$ Department of Biotechnology, Prathyusha Engineering College, Thiruvallur, Chennai, India \\ ${ }^{2}$ Department of Animal Sciences, Manonmaniam Sundaranar University, Tirunelveli, India \\ Email: *ajargnr@gmail.com
}

How to cite this paper: Dhasarathan, P., Devi, N.R., Sangeetha, P., Navaraj, S.M.G., Ranjitsingh, A.J.A. and Padmalatha, C. (2018) Utilisation of Green Synthesised Silver Nanoparticles for Water Quality Management. Advances in Nanoparticles, 7, 77-84.

https://doi.org/10.4236/anp.2018.74007

Received: October 6, 2018

Accepted: November 10, 2018

Published: November 13, 2018

Copyright $\odot 2018$ by authors and Scientific Research Publishing Inc. This work is licensed under the Creative Commons Attribution International License (CC BY 4.0).

http://creativecommons.org/licenses/by/4.0/

\begin{abstract}
In the present study silver nanoparticles $\left(\mathrm{AgNP}_{\mathrm{s}}\right)$ were synthesized using leaves of bamboo plant, Bambus vulgaris and the size of the nanoparticles was confirmed using XRD, EDAX, SEM, TEM, PSA analysis. The antimicrobial activity of the synthesized $\mathrm{NP}_{s}$ showed a good antibacterial activity against the waterborne isolates, E. coli, Staphyllococcus aureus, Vibrio cholera and Salmonella $s p$. Further the anti algal activity of the $\mathrm{NP}_{\mathrm{s}}$ was tested against the algae, Dictyosphaerium pulchellum, and Algoriphagus chordate. The SEM studies revealed that the $\mathrm{AgNP}_{s}$ breaks the cell wall of algae and inhibits the growth. The safe dose of $\mathrm{AgNP}_{s}$ can be used in aquaculture farms, household water tanks and other small water bodies to wipe out waterborne pathogens and algal bloom.
\end{abstract}

\section{Keywords}

Green Synthesized $\mathrm{AgNP}_{s}$, Antialgal $\mathrm{AgNP}_{s}$, Antimicrobial $\mathrm{AgNP}_{s}$, Water Cleaning, Aquaculture and Domestic Water Tanks

\section{Introduction}

Water, an elixir of life has now become a source to carry much water borne illness. Bacterial and neurotoxic algal growth in drinking water bodies affects human health. Unclean household water tanks and public water supply system supports many harmful water borne illness through the microbes, Vibrio cholera, Salmonella typhi, Salmonella paratyphi, Staphyllococcus aureus, E. coli and other enteric pathogens. Further many fresh water bodies are also contaminated with microbes. Algal growth and bacterial contaminants in our household water tanks clog the water taps, affect health and promote several waterborne diseases. 
To find out a safe solution for this menace, green synthesized silver nanoparticles were tried. Algal blooms in water bodies reduce dissolved oxygen content and prevent solar penetration. This leads to eutrophication and challenges to aquatic cultivable species. Some algal bloom decolorizes the water and the consumption of the water with their spores cause many neurological problems. Harmful algal blooms known as red tides, blue green algae or Cyanobacteria, or other harmful algal blooms were reported to cause toxic water bodies and affect human health, aquatic ecosystem and economy. Hence it is imperative to protect the drinking water sources and aquaculture ponds from algal bloom and water borne pathogens. The chemical methods of disinfecting the water bodies lead to other eco-induced harmfulness in human beings. So a safe, non toxic, eco friendly agent is needed to contain pathogenic microbes and algae in water bodies. In this direction the green synthesized silver nanoparticles are good choice [1] [2] [3]. Hence in the present study, silver nano particles were prepared using Bamboo leaves and the potential of green synthesized $\mathrm{AgNP}_{s}$ was tested against water borne bacterial pathogens and algae causing harmful algal bloom (HAB) in water.

\section{Materials and Methods}

Fresh leaves of, Bambusa vulgaris were collected from Anna university, Chennai campus, and washed several times with water to remove the dust particles and then air dried to remove the residual moisture and ground to powder form. The plant extract was prepared by mixing $1 \%$ of plant material with isopropanol $(50 \mathrm{ml})$ in a $250 \mathrm{ml}$ of (Borosil, India) conical flask. Then the solution was incubated for 2 days at room temperature. The supernatant was separated and filtered with filter paper. Then the solution was used for the reduction of silver ions $\mathrm{Ag}^{(+)}$silver nanoparticles $\mathrm{Ag}^{(-)}$.

Firstly a $10 \mathrm{ml}$ solution of $\mathrm{AgNO}_{3}(1 \mathrm{mM})$ is prepared in a beaker and also 5 $\mathrm{ml}$ of bamboo extract solution was prepared. Then $5 \mathrm{ml}$ of $\mathrm{AgNO}_{3}$ was mixed with the bamboo extracts solution. The solution was kept undisturbed for 6 hours. A change in the colour of the solution was observed and the solution turned pale yellowish green colour. The optical absorption spectra of silver nanoparticle were recorded using a UV-Vis PG-T90; initially base line adjustments are performed. The sample was taken in cuvettes with water as the solvent and placed in the setup and the absorption spectra are recorded in the wavelength range $200-900 \mathrm{~nm}$. The prepared particle were analysed by X-Ray Diffraction (XRD) and Transmission Electron Microscope (TEM) methods [2]. Prepared particle were screened against bacterial pathogens by standard methods [1].

\section{Result}

UV visible spectroscopy: UV-Visible spectroscopy was performed in spectrophotometer using distilled water as blank. The spectroscopy was performed for absorbance between the range of $200-900 \mathrm{~nm}$. In green synthesized solution the peak was observed at $422 \mathrm{~nm}$ (Figure 1). Silver nanoparticle showed the peak 
between the range of $390-430 \mathrm{~nm}$ and this indicates the presence of silver nanoparticles in our sample (Figure 2).

Microscope analysis: The particles synthesized are spherical in shape. They are smallest in size and are monodispersed in nature as analyzed by SEM (Figure 3) and TEM (Figure 4, Figure 5). Also the agglomeration which is due to the surface charge of the nanoparticles was observed. The nanoparticles are square shaped and are present in different size. This method has modified the shape of the $\mathrm{AgNP}_{s}$ which has same size (Figure 6).

Antimicrobial activity of silver nanoparticles: The antimicrobial activity of Ag nanoparticles was investigated against Escherichia coli, Staphylococcus aureus and Vibrio cholera (Table 1). In these tests, Muller Hinton agar plates were used and Ag nanoparticles of various concentrations were supplemented in liquid systems. The results showed that $E$. coli were inhibited at a low concentration of Ag nanoparticles, whereas the growth-inhibitory effects on $S$. aureus were mild. Disruption of algal cell is more pronounced in green synthesized silver nano particle treatment and algal cell wall got ruptured (Figures 7-9).

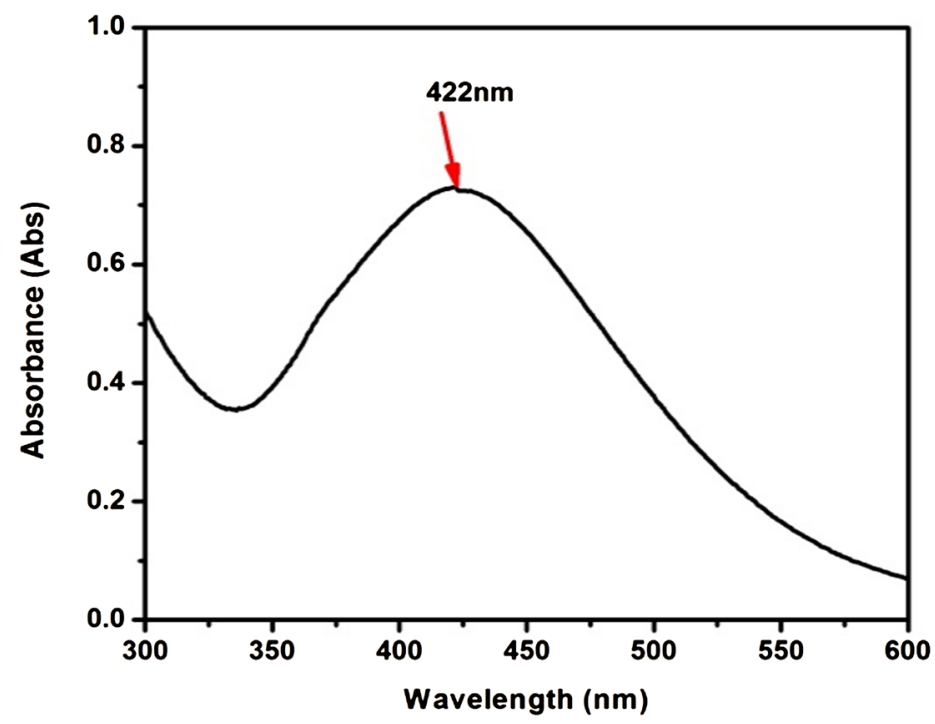

Figure 1. UV-Vis-Spectrum of Ag nanoparticle (Green synthesis).

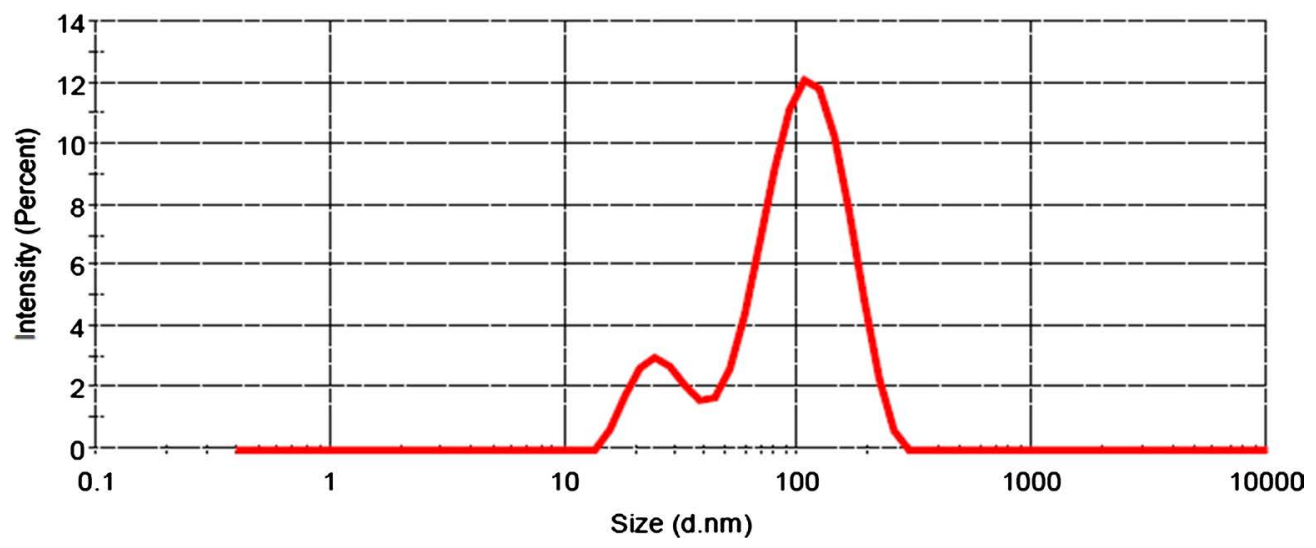

Figure 2. X-ray diffraction of synthesized nanoparticles. 


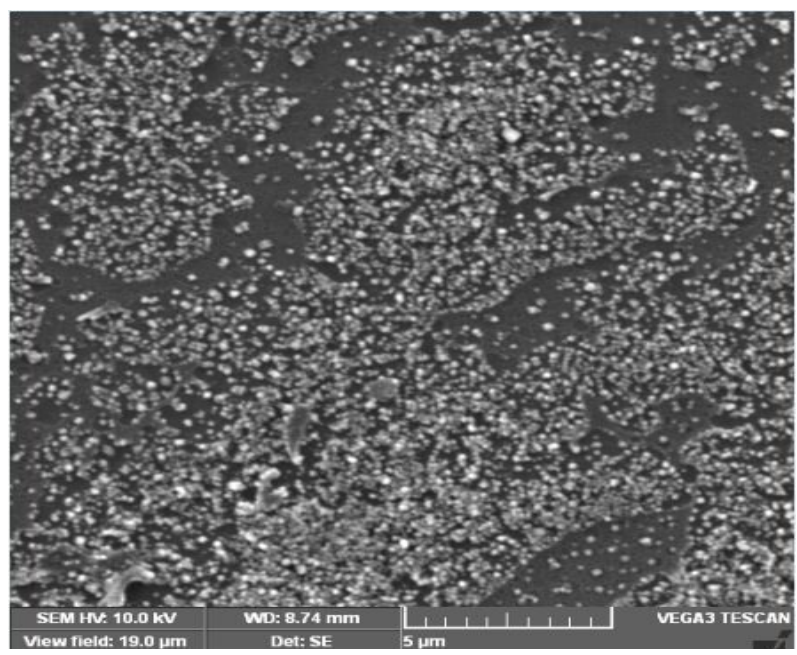

Figure 3. SEM images of green synthesised $\mathrm{AgNP}_{s}$.

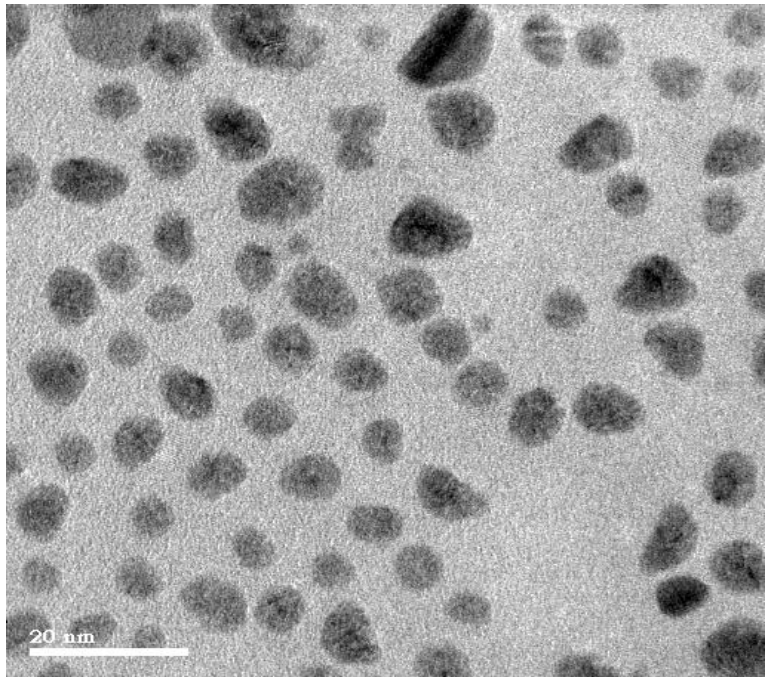

Figure 4. TEM image for Green synthesized $\mathrm{AgNP}_{s}$.

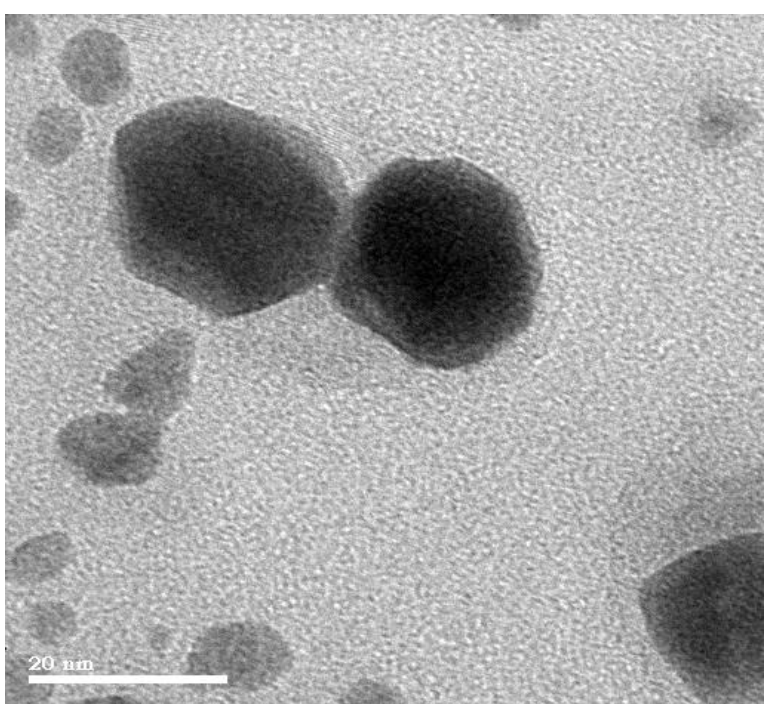

Figure 5. TEM image of Green synthesized $\mathrm{AgNP}_{s}$. 
Results

Z-Average (d.nm): 57.54

Pdl: 0.505

Intercept: 0.811
Size (d.nm...

Peak 1: 106.6

Peak 2: $\quad 4404$

Peak 3: $\quad 0.000$
\% Intensity: St Dev (d.n...

98.6

74.82

1.4

919.2

0.0

0.000

\section{Result quality Refer to quality report}

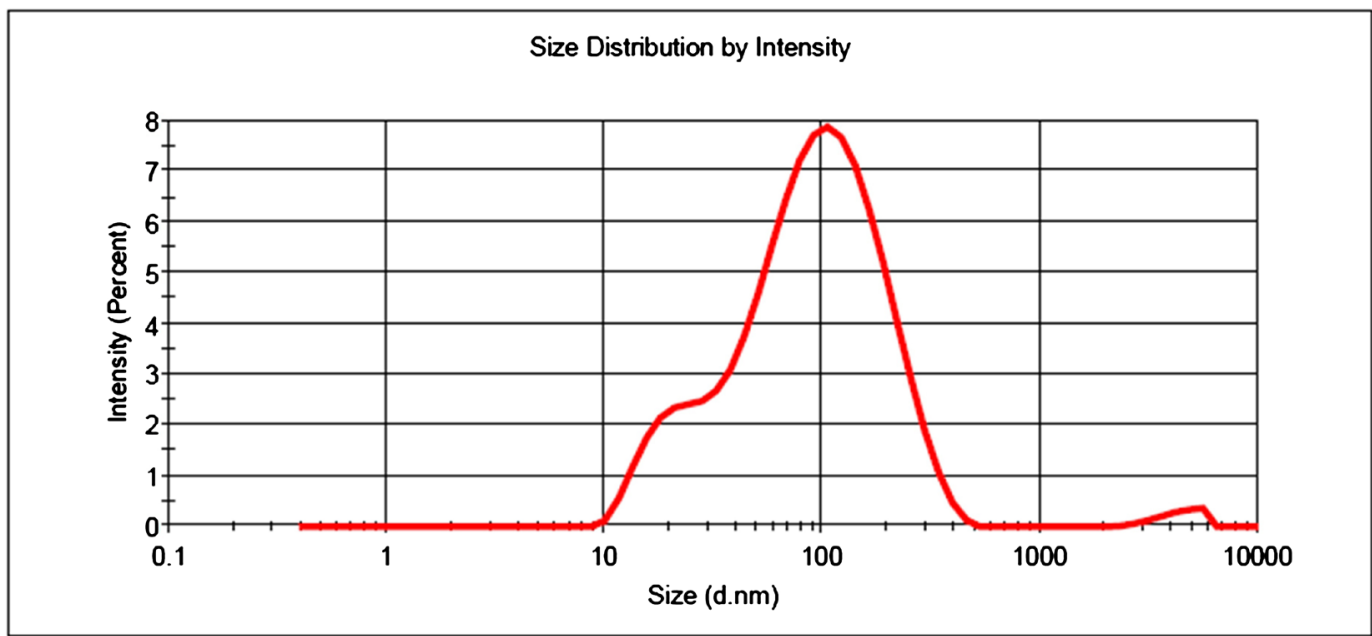

Figure 6. Particle size analyzer graphs of green synthesised $\mathrm{AgNP}_{s}$.

Table 1. Antimicrobial activity of $\mathrm{AgNP}_{\mathrm{S}}$.

\begin{tabular}{ccccc}
\hline \multirow{2}{*}{$\begin{array}{c}\text { AgNP }_{\text {s }} \\
\text { Concentration }(\mu \mathrm{l})\end{array}$} & \multicolumn{4}{c}{ Inhibition assay zones of inhibition (mm) } \\
\cline { 2 - 5 } & S. aureus & V. cholerae & E. coli & S. typhii \\
\hline 10 & 12 & 13 & 12 & 12 \\
20 & 13 & 13 & 12 & 14 \\
30 & 13 & 15 & 12 & 16 \\
40 & 14 & 16 & 14 & 17 \\
50 & 15 & 16 & 14 & 18 \\
\hline
\end{tabular}

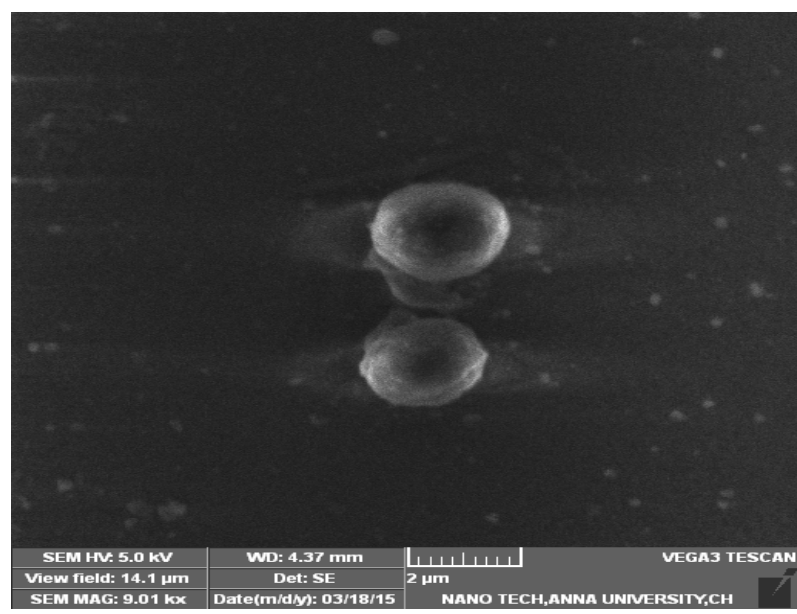

Figure 7. SEM image of algae (control). 


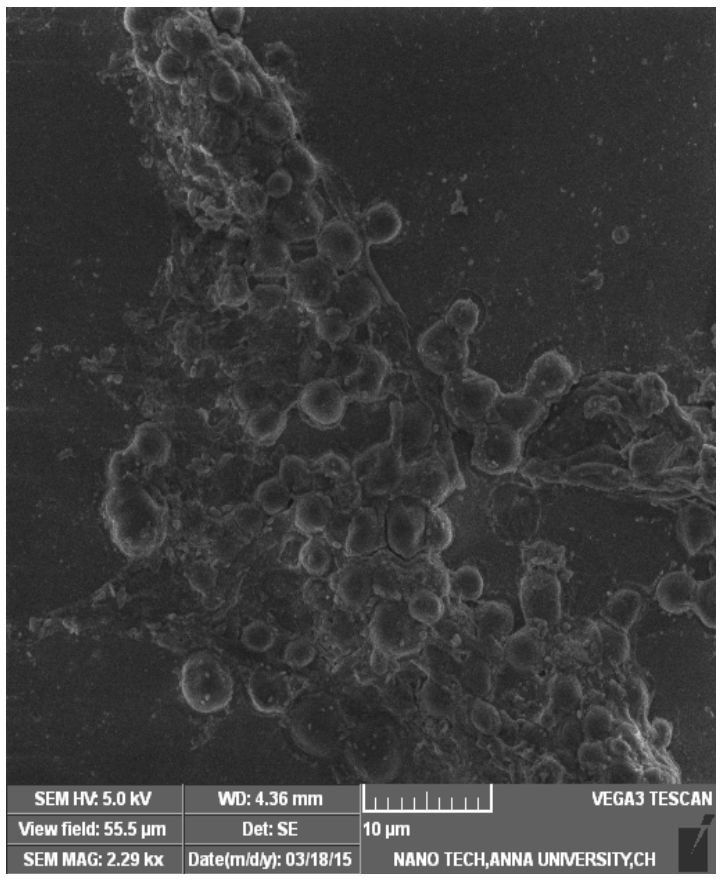

(a)

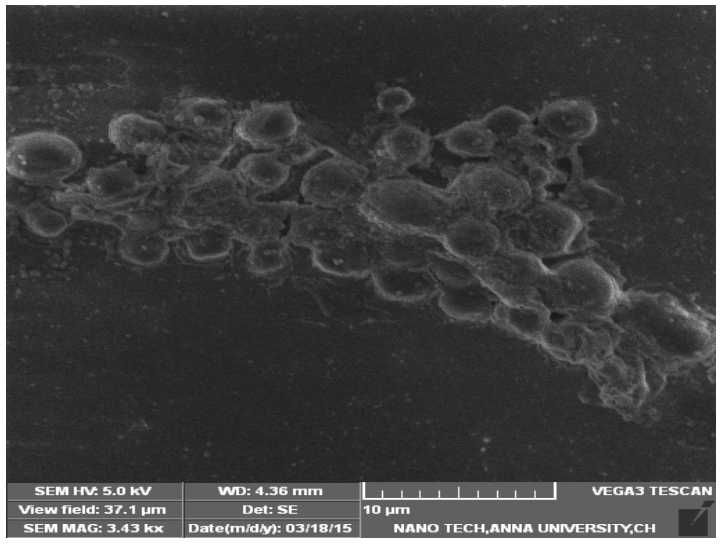

(b)

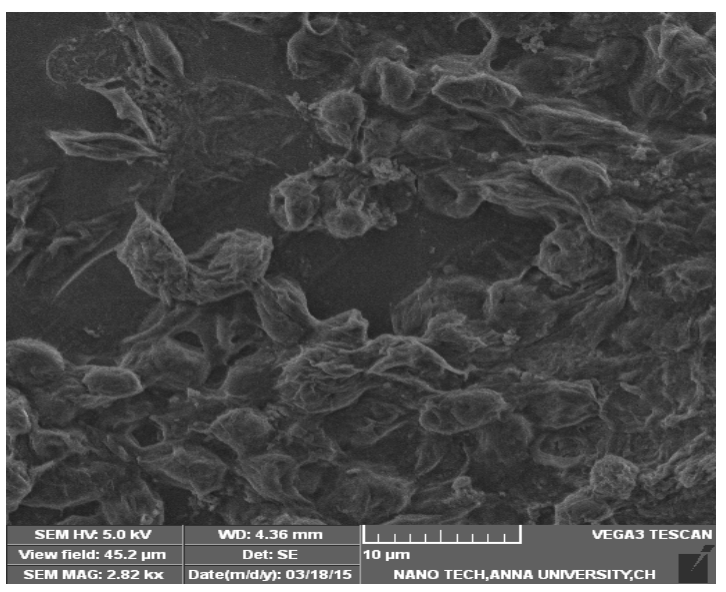

(c)

Figure 8. SEM image showing control (a) and $\mathrm{AgNP}_{\mathrm{s}}$ treated A. chlordae with broken and clumbed cells ((b), (c)). 


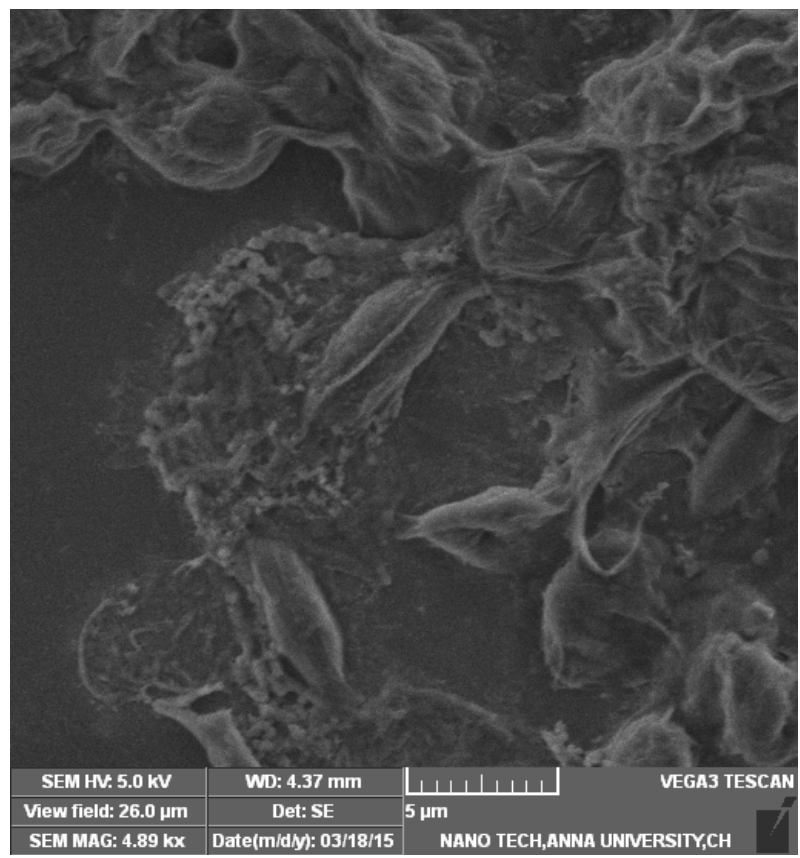

Figure 9. Ruptured cell wall of algae due to treatment with $\mathrm{AgNP}_{s}$.

\section{Discussions}

Nanoscience is revolutionizing many aspects of bioscience today. For the safe environmental approach, nanoparticles are synthesized using plant extracts and used in various medical applications. In the present study silver nanoparticles $\left(\mathrm{AgNP}_{\mathrm{s}}\right)$ were prepared. The morphology and size of the $\mathrm{AgNP}_{\mathrm{s}}$ were studied using UV, TEM, SEM, XRD, EDAX and PSA. Using the extracts of the leaves of the bamboo leaves the $\mathrm{AgNP}_{\mathrm{s}}$ were prepared and tested for antibacterial and anti algal bloom activities. The study showed that the green synthesized $\mathrm{AgNP}_{s}$ have good antibacterial activities. The water borne pathogens E. coli, $V$. cholerae, Salmonella typhii and $S$. aureus tested against $\mathrm{AgNP}_{3}$ showed high inhibition for Salmonella typhii $(18 \mathrm{~nm})$ at a dose of $50 \mu \mathrm{l}$ and little less $(16 \mathrm{~nm})$ for $V$. cholerae. The study indicates a good antibacterial activity. The silver ions in the $\mathrm{AgNP}_{s}$ were reported to damage the cell membranes in bacterial cell and affecting the membrane functions and cell physiology [4].

The action of silver ion $\mathrm{AgNP}_{\mathrm{s}}$ on the membrane or cell boundary was confirmed by its action against the cell wall of the two species of algae chosen. SEM study confirmed the damage to cell boundary. Of the two micro algae chosen cell wall rupture is more prominent in Algoriphagus chordae than Dictyosphaerium pulchellum. Aharodnik et al., [5] reported that $\mathrm{AgNP}_{s}$ damages cell membraene and plasma in bacteria by cell wall tearing, causing exhaustion of the intracellular adenosine triphosphate. Algal bloom in water bodies particularly in aquaculture ponds and drinking water source cause several harmful effects. Algal bloom not only alters the physico-chemical quality of water but also affects its utility by releasing toxins, hazardous to human health [6]. From the results of the present study it is evident that biogenic synthesis of silver nanoparticles using bamboo 
leaves are potential water cleaning agent.

\section{Acknowledgements}

Authors are very much thankful to the Management and Principal of Prathyusha Engineering college, Chennai for providing facility to carry out this work in lab.

\section{Conflicts of Interest}

The authors declare no conflicts of interest regarding the publication of this paper.

\section{References}

[1] Devanesan, S., AlSalhi, M.S., Balaji, R.V., Ranjitsingh, A.J.A., et al. (2018) Antimicrobial and Cytotoxicity Effects of Synthesized Silver Nanoparticles from Punica granatum Peel Extract. Nanoscale Research Letters, 13, 315-321. https://doi.org/10.1186/s11671-018-2731-y

[2] Dhasarthan, P., Ranjitsingh, A.J.A. and Padmalatha, C. (2017) Antimicrobial Activity of Selected Nano Preparations of Traditional Medicine against Human Pathogens. International Journal of Advance Research in Science and Engineering, 6, 1019-1027.

[3] Dhasarthan, P., Ranjitsingh, A.J.A. and Gajendravarathan, S. (2017) Supremacy of STR-UMDNA Based Han Identity Testing a Comparison with Other Forensic Testing. International Journal of Engineering Technology Science and Research, 4, 690-695.

[4] Thuy, D.T., Thane, L.S. and Kien, N.T. (2016) Inhibition Effect of Engineered Silver Nanoparticles to Bloom Forming Cyanobacteria. Advances in Natural Sciences. Nanoscience and Nanotechnology, 7, Article ID: 035018.

[5] Mariselvam, R., Ranjitsingh, A.J.A., Usha Raja Nanthini, A., Kalirajan, K., Padmalatha, C. and Mosae Selvakumar, P. (2014) Green Synthesis of Silver Nanoparticles from the Extract of the Inflorescence of Cocos nucifera (Family: Arecaceae) for Enhanced Antibacterial Activity. Spectrochimica Acta Part A: Molecular and Biomolecular Spectroscopy, 129, 537-541. https://doi.org/10.1016/j.saa.2014.03.066

[6] Rao, B. and Tang, R.C. (2017) Green Synthesis of Silver Nanoparticles with Antibacterial Activities Using aqueous Eriobotrya japonica Leaf Extract. Advances in Natural Sciences. Nanoscience and Nanotechnology, 8, Article ID: 015014. 